\title{
Biomechanical investigation of titanium and zirconia dental implants
}

\author{
M. Ruzas*, A. Šešok** \\ *Vilnius Gediminas Technical University, J. Basanavičiaus 28, 03224 Vilnius, Lithuania, \\ E-mail: mindaugas.ruzas@stud.vgtu.lt \\ **Vilnius Gediminas Technical University, J. Basanavičiaus 28, 03224 Vilnius, Lithuania, E-mail: andzela.sesok@vgtu.lt \\ cross $^{\text {ref }}$ http://dx.doi.org/10.5755/j01.mech.23.4.15269
}

\section{Introduction}

Titanium dental implants are widely used in Lithuania and all around the world. Recent studies suggest that some patients could be allergic to some additives of titanium alloys (approx. 1\% of total cases) [1]. Furthermore specific reactions may be resulted, when small metal particles spread in surrounding tissues. Macrophages attempts to engulf and digest these particles and results in inflammatory reaction. Therefore titanium dental implants are not recommended for patients who are more susceptible to inflammatory diseases. Regardless excellent material properties of titanium dental implants and ability to osseointegrate, titanium dental implants lack aesthetics. Silver color metal is often visible through the gums (Fig. 1).

Zirconia dental implants are potential alternative to titanium dental implants. Ceramics are polycrystalline compounds, usually inorganic [2]. Zirconia is a very durable white color material. Aesthetic properties of zirconia dental implants are very close to the natural teeth (Fig. 1). Mechanical properties of zirconia are superior to some metal alloys $[3,4]$. Zirconia dental implants are inert and also are has ability to osseointegrate. Furthermore inflammatory reactions to ceramic particles are reported to be milder than those evoked by metal implants [5]. In contrast to metals, ceramics are less elastic and practically not susceptible to creep. Therefore ceramic dental implants are very susceptible to microcracks. However if a ceramic is flawless, it is very strong even when subjected to tension [2].

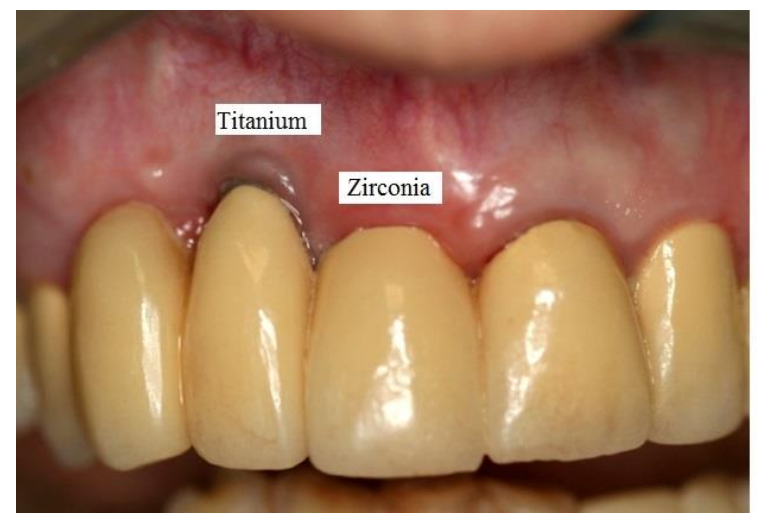

Fig. 1 Titanium versus zirconia implant [6]

Up to this point zirconia was only used as a coating material for metal dental implants. Advancement in manufacturing process of ceramics led to the opportunity to produce dental implants entirely from zirconia. Although material properties are auspicious, it is still early to discuss longterm success of zirconia dental implants.
Durability of dental implants is one of the most important fields of research in modern odontology. Dental implant success is closely related to the quality of osseointegration process and artificial material's ability to survive in aggressive biological environment. In order to apply novel techniques and materials in practice, clinical researches must be made to ensure that these products are capable to withstand loads which occur during mastication.

Removal torque tests often are used to evaluate the strength of bone-implant interface [7-10]. These experimental studies are time and cost consuming. Moreover tests are being carried out with living animals.

Finite element studies allow researchers to simulate loading of object of interest and assess as well as compare different materials and parameters. The modeling process of desirable object is the most important stage of these studies. The model of the bone could be based on computed tomography or magnetic resonance tomography images [11]. According Li, the accurate determination of boundary between cortical and trabecular bone is a complex task, therefore this boundary line is approximated [11]. Not only composition of the bone can be simplified, but geometric shape also. Chang simplified bone structure to a cubic shape, which was covered with a $2 \mathrm{~mm}$ layer of cortical bone [12]. El Anwar simplified bone geometry and simulated as a cylinder that consists of two co-axial cylinders [13]. The model may be two-dimensional. Guan performed a two-dimensional bone-implant structural analysis [14]. According to Guan, two-dimensional model is as precise as three-dimensional, but requires less computing time.

Artificial materials for example implant body, abutment and dental crown, can be modeled quite accurately. Materials are considered to be homogenous and isotropic [11-14]. Loading conditions can be simulated with axial and non-axial forces. If model consists only of bone and implant body, loading forces act on a crest module [13, 14]; if model consists all parts including dental crown loading forces act on the surface of dental crown [12]. Dental implants are subjected to loading conditions from $25 \mathrm{~N}$ up to $500 \mathrm{~N}$ at 15-45 degrees angle [11-14].

The aim of this study is to evaluate and compare the stresses, resulted by dental implants with different materials (titanium alloy and zirconia) and geometrical parameters (length and diameter).

\section{Materials and methods}

In this work a fragment of mandible of adult was modeled, specifically the area around right side first molar tooth. Models were created with Autodesk Inventor 2016 
Professional CAD software. The von Mises equivalent stress was computed for cortical and trabecular bone.

The structure of the bone was simplified and consisted of cortical and trabecular bone. The height of the bone was $27.0 \mathrm{~mm}$, width $-14.0 \mathrm{~mm}$. The thickness of the cortical bone was selected from adult male mandible dimensions statistical data. The layer of cortical bone was assumed to be $2.25 \mathrm{~mm}$ thick.

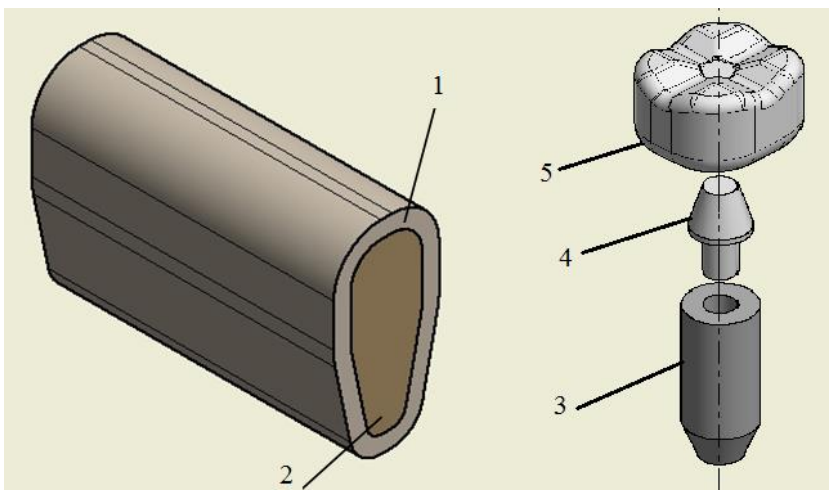

Fig. 2 Three-dimensional bone and implant model: 1 - cortical bone; 2 - trabecular bone; 3 - implant body; 4 abutment; 5 - dental crown

Dental implant consisted of three main parts: implant body, abutment and dental crown (Fig. 2). The geometry of dental crown was based on first molar tooth average dimensions. Implant body was simplified and modeled as a cylinder with a chamfered end. The main parameters of implant body were its diameter $D$ and length $L$. 32 different dental implant designs used in this study cover the diameter range from 3.5 to $6.5 \mathrm{~mm}$ and length range from 8.0 to 17.0 $\mathrm{mm}$. Dental implants were made of titanium alloy Ti-6Al$4 \mathrm{~V}$ and yttria stabilized zirconia (3Y-TZP). The material for abutment was chosen the same as implant body. Dental crowns in all models were made from 3 Y-TZP.

Table 1

Material properties adopted in the study

\begin{tabular}{|c|c|c|c|}
\hline Material & $\begin{array}{c}\text { Young's } \\
\text { modulus, } \\
\text { GPa }\end{array}$ & Poisson's ratio & $\begin{array}{c}\text { Refer- } \\
\text { ence }\end{array}$ \\
\hline Ti-6Al-4V & 110 & 0.35 & {$[15]$} \\
\hline 3Y-TZP & 220 & 0.31 & {$[16]$} \\
\hline $\begin{array}{c}\text { Cortical } \\
\text { bone }\end{array}$ & 13.7 & 0.30 & {$[17]$} \\
\hline $\begin{array}{c}\text { Trabecular } \\
\text { bone }\end{array}$ & 1.5 & 0.30 & {$[13]$} \\
\hline
\end{tabular}

Both the implant and the bone were assumed to be isotropic, homogenous and linear elastic. Material properties used in this study are listed in Table 1.

All physical, chemical properties and requirements for zirconia are listed in ISO 13356:2008 [18].

Force application was performed in vertical conditions using three forces (Fig. 3). One of them was axial and the rest was non-axial. The magnitude of forces was the same and equal $70 \mathrm{~N}$ each. The forces were applied on a dental crown. The exact points of loading were selected according natural points of contact on the dental crown during occlusion [19].

The model was constrained with fixed constraints at both ends of the bone fragment (Fig. 3). Implant was assumed to be fully osseointegrated with the bone, therefore these parts were bonded. Furthermore, all parts of the model were bonded together.

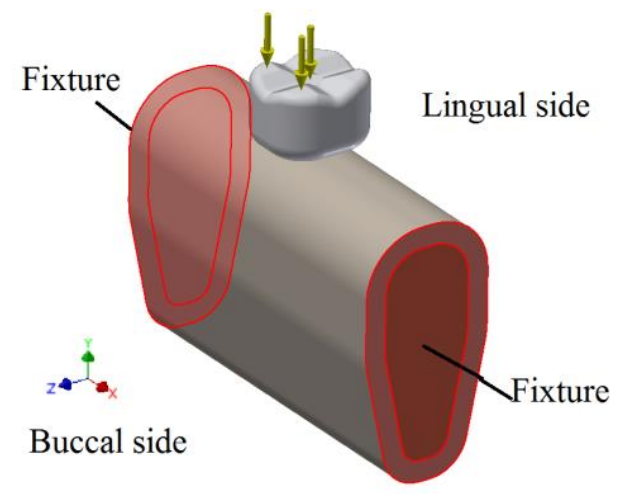

Fig. 3 Loading and fixture of the model

Model was meshed into tetrahedral shape finite elements. The number of finite elements ranged from 133148 to 239858 , with 201550-351595 notches.

\section{Results}

Finite element analysis has shown that highest von Mises stresses in cortical bone were found with titanium alloy implant with diameter of $3.5 \mathrm{~mm}$ and length of $8.0 \mathrm{~mm}$. Peak stress value in cortical bone was $45.85 \mathrm{MPa}$. Calculated stresses were lower than yield strength of cortical bone. Highest stresses were concentrated in upper region of cortical bone on the buccal side of the mandible (Fig. 4). Loading resulted in $10.58 \mu \mathrm{m}$ displacement in cortical bone.

Lowest stresses in cortical bone were found with zirconia implant with diameter of $6.5 \mathrm{~mm}$ and length of $17.0 \mathrm{~mm}$ (Fig. 5). Peak stress value in cortical bone was 6.65 MPa, displacement $-5.14 \mu \mathrm{m}$.

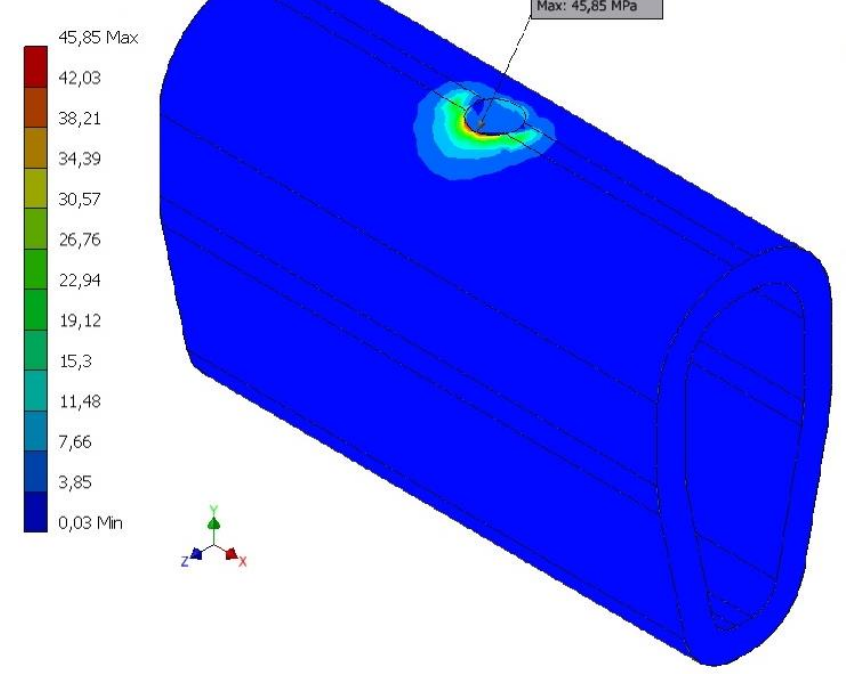

Fig. 4 Von Mises stresses in cortical bone caused by Ti-6Al$4 \mathrm{~V}$ implant $(D=3.5 \mathrm{~mm} ; L=8.0 \mathrm{~mm})$ 

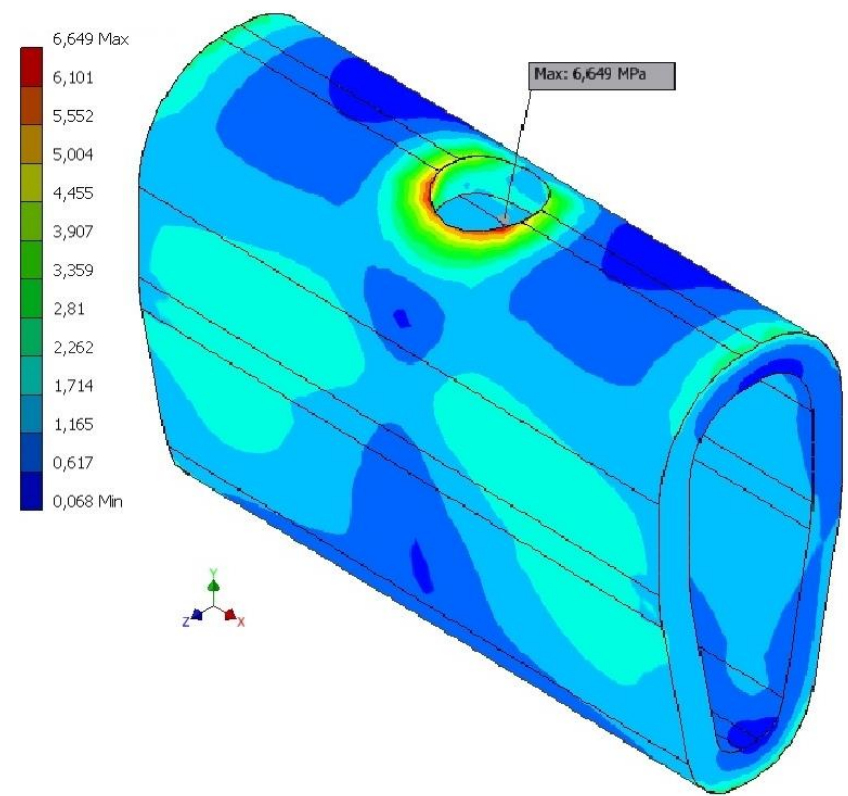

Fig. 5 Von Mises stresses in cortical bone caused by $3 \mathrm{Y}$ TZP implant $(D=6.5 \mathrm{~mm} ; L=17.0 \mathrm{~mm})$

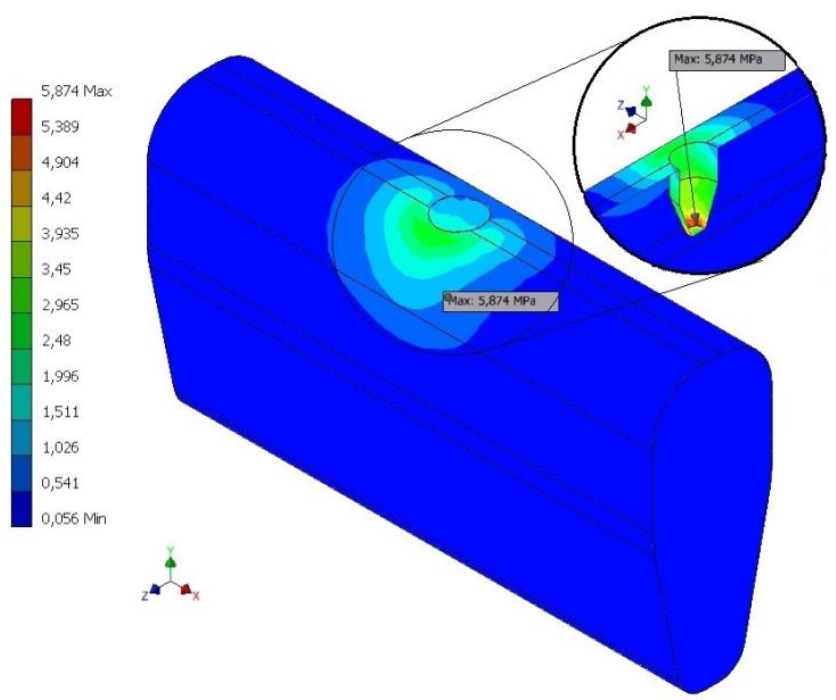

Fig. 6 Von Mises stresses in trabecular bone caused by $3 \mathrm{Y}$ TZP implant $(D=3.5 \mathrm{~mm} ; L=8.0 \mathrm{~mm})$

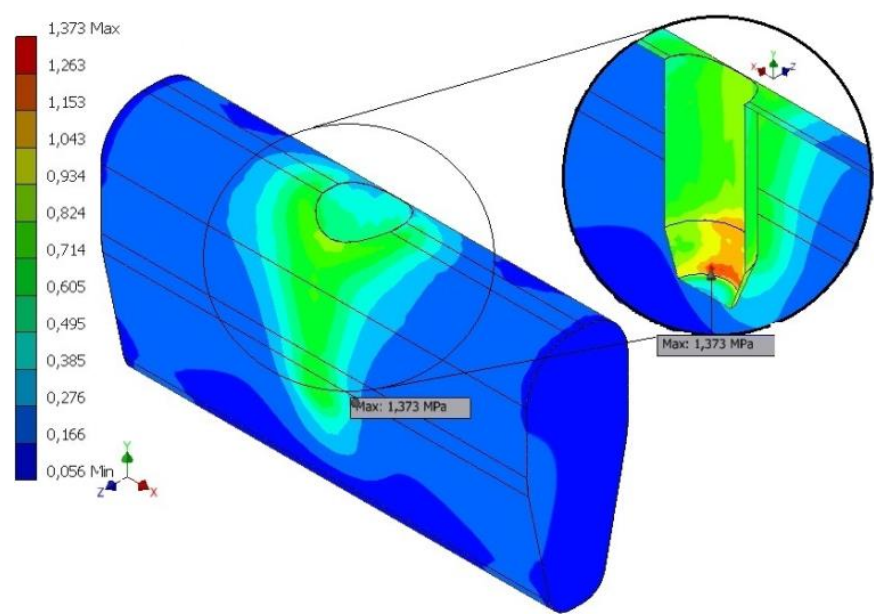

Fig. 7 Von Mises stresses in trabecular bone caused by Ti6Al-4V implant $(D=6.5 \mathrm{~mm} ; L=17.0 \mathrm{~mm})$

Von Mises equivalent stresses in trabecular bone were 7.5 times lower than stresses in cortical bone. Highest von Mises stresses in trabecular bone were found with zirconia implant with diameter of $3.5 \mathrm{~mm}$ and length of $8.0 \mathrm{~mm}$. Peak stress value in trabecular bone was $5.87 \mathrm{MPa}$ (Fig. 6). Maximum displacement was $8.8 \mu \mathrm{m}$.

Lowest stresses in trabecular bone were found with titanium alloy implant with diameter of $6.5 \mathrm{~mm}$ and length of $17.0 \mathrm{~mm}$. Peak stress value in trabecular bone was 1.37 MPa (Fig. 7). The stresses distributed in larger area than compared with smaller diameter and length dental implants. The maximum displacement of trabecular bone was $5.11 \mu \mathrm{m}$.

The increase of implant diameter and length reduced stress values in both cortical and trabecular bone (Figs. 8-9). Maximum stress values in cortical bone with zirconia implants were noticeably lower than with titanium alloy implants. Major difference was calculated with $3,5 \mathrm{~mm}$ dental implants, where von Mises stress peak values differed from 8.48 to $9.06 \mathrm{MPa}$.

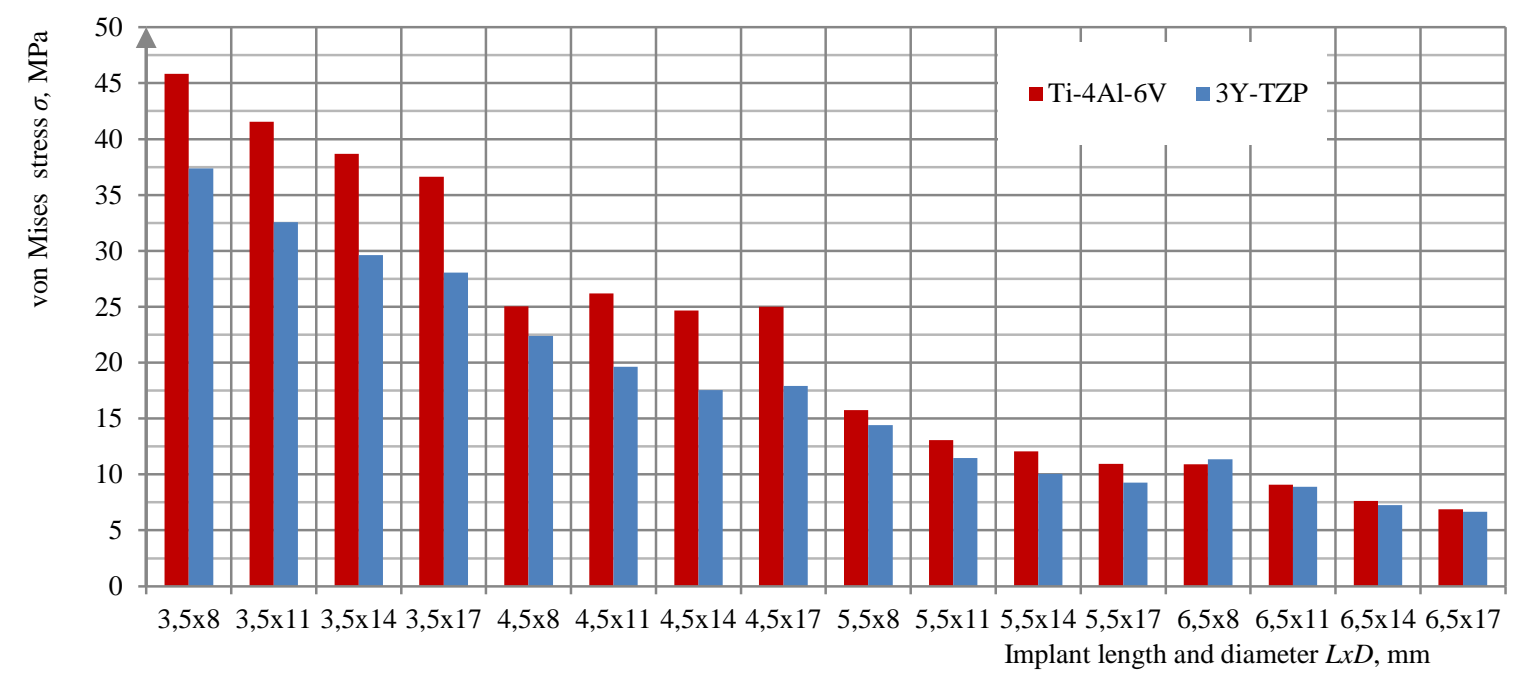

Fig. 8 Von Mises stresses in cortical bone 


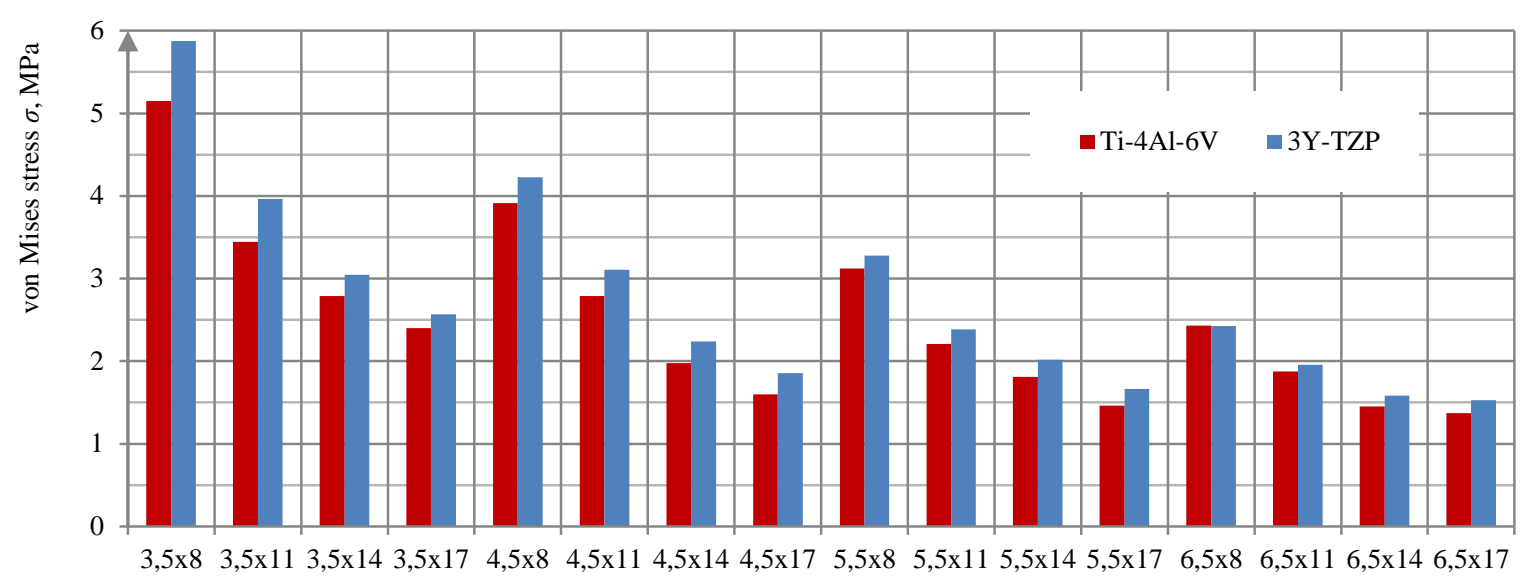

Implant length and diameter $L x D, \mathrm{~mm}$

Fig. 9 Von Mises stresses in trabecular bone

The difference in generated stresses between zirconia and titanium alloys dental implants were $50 \%$ lower with implant diameter of $4.5 \mathrm{~mm}$. Stress differences with $5.5 \mathrm{~mm}$ implants were only from 1,36 to $2.02 \mathrm{MPa}$, while tests with largest diameter used in this study, $6.5 \mathrm{~mm}$, resulted no noticeable difference.

The peak stresses in trabecular bone were found to be lower with dental implants from titanium alloy. Maximum von Mises stresses were 9.8\% lower, compared to the dental implants from zirconia with the respective geometrical parameters. The increase of implant geometrical parameters resulted in decrease of the stress difference between two materials.

From a biomechanical point of view, zirconia implants may be a potential alternative to conventional titanium implants for the support of overdentures. Superior aesthetic properties and lower peak stresses in cortical bone suggest that zirconia dental implants may be recommended to be used for front teeth such as incisors and canines. The material of the dental implant for molar and premolar teeth, which are deeper in the mouth and where larger implants usually are used, may be chosen after considering a possible specific reaction to one of the material of a particular patient.

\section{Discussion}

Finite element analysis is a widely used method for stress determination in physical structures. The results of these studies depend on various factors, such as material properties, boundary conditions, body interface definition, etc. It is apparent that this study was only a simulation of clinical situation.

The simplification of the model resulted in decrease of modeling and computing time. For instance, geometrical shape of dental implant was simplified and replaced with cylinder shaped object, instead of screw type dental implant used in clinical practice. Both bone and implant were assumed to be isotropic and homogenous, while in reality the determination of anisotropic properties of human bone is practically impossible. Nevertheless the results were not affected by these simplifications, because the purpose of the study was to compare the stresses, resulted by dental implants with different materials and geometrical parameters.
The comparison of results of various studies is complicated, because of different model parameters, material properties, boundary conditions used in these studies. The comparison could be only made by analyzing patterns of stress distribution, resulted from variation of different parameters. The results of this study confirm the conclusions of many authors that highest bone stresses occur in the cortical bone near the neck of the implant. Huang reported stresses in the cortical bone to be 9.5 times higher than in trabecular bone [20]. This study determined this ratio to be 7.5. This suggests that the major loading is carried by cortical bone.

The distribution of the stresses and peak values are mostly affected by geometrical parameters of dental implant. Himlova concluded that the increase of diameter of dental implant is more effective than the increase of length [21]. El-Anwar and El-Zawahri reported that stress distribution caused by wide implants (5-6 mm in diameter) was not affected by the change of implant length [13].

Comparative studies suggest that zirconia and titanium dental implants resulted similar stress levels in the bone, and thus zirconia is suitable material for application in dental implants. Chang determined that peak stress values with zirconia dental implants were 9\% lower than titanium [12]. Meanwhile titanium dental implant resulted in $15 \%$ lower stresses in trabecular bone.

Presumably, finite element analysis will remain one of main methods in dental research in order to determine and compare the effectiveness of different materials and parameters. The advancement in medical imaging techniques, such as micro-CT or MRT, proposes a possibility to build more precise models of the living structure. Moreover, these images may be used for pre-operative assessment and planning. This course of development may increase the reliability of results in finite element analysis.

\section{Conclusions}

1. Peak stress values in cortical bone were $19.1 \%$ lower with zirconia dental implants than titanium alloy. The major advantage of zirconia dental implants was found with small dental implants (3.5 and $4.5 \mathrm{~mm}$ in diameter). Significant difference between bone stresses generated by different material large diameter implants $(5.5$ and $6.5 \mathrm{~mm}$ ) was not observed. 
2. Peak stress values in trabecular bone were 9.8\% lower with titanium alloy dental implants than zirconia.

3. Analysis has shown that zirconia dental implants can be used as an alternative to titanium dental implants.

\section{References}

1. Osman, R.B.; Elkhadem, A.H.; Ma, S.; Swain, M.V. 2013. Titanium versus zirconia implants supporting maxillary overdentures: three-dimensional finite element analysis, The International Journal of Oral \& Maxillofacial Implants. Sep-Oct; 28(5): 198-208

2. Park, J. B.; Bronzino, J. D. 2003. Biomaterials: principles and applications, Boca Raton, London: CRC Press 38-50.

3. Osman, R.B.; Swain, M.V. 2015. A Critical Review of Dental Implant Materials with an Emphasis on Titanium versus Zirconia, Materials: 8: 932-958. http://dx.doi.org/10.3390/ma8030932.

4. Apratim, A., et al. 2015. Zirconia in dental implantology: A review, Journal of International Society of Preventive \& Community Dentistry,5(3):147-156. http://dx.doi.org/10.4103/2231-0762.158014.

5. Ozkurt, Z.; Kazazoglu, E. 2011. Zirconia dental implants: a literature review, Journal of oral implantology 37(3): 367-376.

http://dx.doi.org/10.1563/AAID-JOI-D-09-00079.

6. Titanium versus zirconia implant. Available from Internet: http://www.milesofsmilesdental.net/750/biocompatible-esthetic-white-dental-implants/

7. Azlubaydi, T. L. 2009. In vivo studies of the ceramic coated titanium alloy for enhaced osseointegration in dental applications, Journal of Materials Science: Materials in Medicine, 20 Suppl.1:S: 35-42.

8. Furguson, S.J., et al. 2008. Biomechanical comparison of different surface modifications for dental implants, International Journal of Oral and Maxillofacial Implants 23(6): 37-46.

9. Gahlert, M., et al. 2007. Biomechanical and histomorphomertric comparison between zirconia implants with varying surface textures and a titanium implant in the maxilla of miniature pigs, Clinical oral implants research 18: 662-668. http://dx.doi.org/10.1111/j.1600-0501.2007.01401.x.

10. Sennerby, L., et al. 2005. Bone tissue responses to surface-modified zirconia implants: a histomorphometric and removal torque study in the rabbit, Clinical implant dentistry and related research, 1:S. 13-20. http://dx.doi.org/10.1111/j.1708-8208.2005.tb00070.x.

11.Li, Z., et al. 2014. Three dimensional finite element analysis of a novel osteointegrated dental implant designed to reduce stress peak of cortical bone, Acta of $\mathrm{Bi}$ oengineering and Biomechanics 16(3): 21-28.

12. Chang, H.S., et al. 2012. Stress distribution of two commercial dental implant systems: a three dimensional FEA, Journal of Dental Sciences 8: 261-271. http://dx.doi.org/10.1016/j.jds.2012.04.006.

13. El-Anwar, M.; El-Zawahry, M. 2011. A three dimensional finite element study on dental implant design, Journal of Genetic Engineering and Biotechnology 9: $77-82$.

http://dx.doi.org/10.1016/j.jgeb.2011.05.007.
14. Guan, H., et al. 2009. Influence of bone and dental implant parameters on stress distribution in the mandible a finite element study, The International Journal of Oral and Maxillofacial Implants 24(5): 866-876.

15. Benzing U. R. et al. 1995. Biomechanical aspects of two different implant-prosthetic concepts for edentulous maxillae, International Journal of Maxillofacial implants, 10:188-198 p.

16. Osman, R. 2013. Prosthodontic Outcome of Zirconia Implants Supporting Overdentures. New Zealand. 23p.

17. Quaresma, S. E. T., et al. 2008. A finite element analysis of two different dental implants: stress distribution in the prosthesis, abutment, implant, and supporting bone, Journal of Oral Implantology 34(1) :1-6.

http://dx.doi.org/10.1563/15481336(2008)34[1:AFEAOT]2.0.CO;2.

18. International standard ISO 13356. 2008. Implants for surgery - Ceramic materials based on yttria-stabilized tetragonal zirconia (Y-TZP)

19. Occlusion (Dental Anatomy, Physiology and Occlusion) Part 4 [online], [accessed May 1st 2016]. Available from Internet: http://what-when-how.com/dental-anatomyphysiology-and-occlusion/occlusion-dental-anatomyphysiology-and-occlusion-part-4/.

20. Huang, S. C.; Tsai, C. F. 2003. Finite element analysis of a dental implant, Biomedical engineering-applications, basis and communications 15(2): 82-86. http://dx.doi.org/10.4015/S1016237203000134.

21. Himlova, L., et al. 2004. Influence of implant length and diameter on stress distribution: finite element analysis, The Journal of Prosthetic Dentistry 91(1): 20-26. http://dx.doi.org/10.1016/j.prosdent.2003.08.008.

\section{Ruzas, A. Šešok}

\section{BIOMECHANICAL INVESTIGATION OF TITANIUM AND ZIRCONIA DENTAL IMPLANTS}

S u m m a r y

This paper presents results from using a three-dimensional finite element model to investigate the stress level in surrounding bone as a function of implant material, diameter and length. Three-dimensional model of dental implant and bone was created using Autodesk Inventor 2016. The 32 different implant designs used in this study cover the diameter range from 3.5 to $6.5 \mathrm{~mm}$, length range from 8.0 to $17.0 \mathrm{~mm}$ and materials - zirconia and titanium alloy. Models were subjected to loading of 1 axial and 2 non-axial forces, all equal to $70 \mathrm{~N}$. Analysis of results showed that increase in implant diameter and length generated lower stresses in both cortical and trabecular bone. Stresses in cortical bone were on average $19.1 \%$ lower using zirconia dental implants. Titanium dental implants resulted in $9.8 \%$ lower stresses in trabecular bone.

Keywords: dental implants, durability research, finite element analysis, numeric stress analysis, osseointegration, titanium, zirconia.

Received June 14, 2016 Accepted August 04, 2017 